Bing-Jie Hou, Ibrahim Omar Osman, Dong-Cheng Hu and Jia-Cheng Liu*

\title{
Crystal structure of catena-poly[tetraiodido- $\left(\mu_{2}-1\right.$, 4-bis(2-methyl-1H-imidazol-1-yl)benzene- $\left.\mathrm{K}^{2} \mathrm{~N}: \mathrm{N}^{\prime}\right)$ dimercury(II)], $\mathrm{C}_{14} \mathrm{H}_{14} \mathrm{Hg}_{2} \mathrm{I}_{4} \mathrm{~N}_{4}$
}
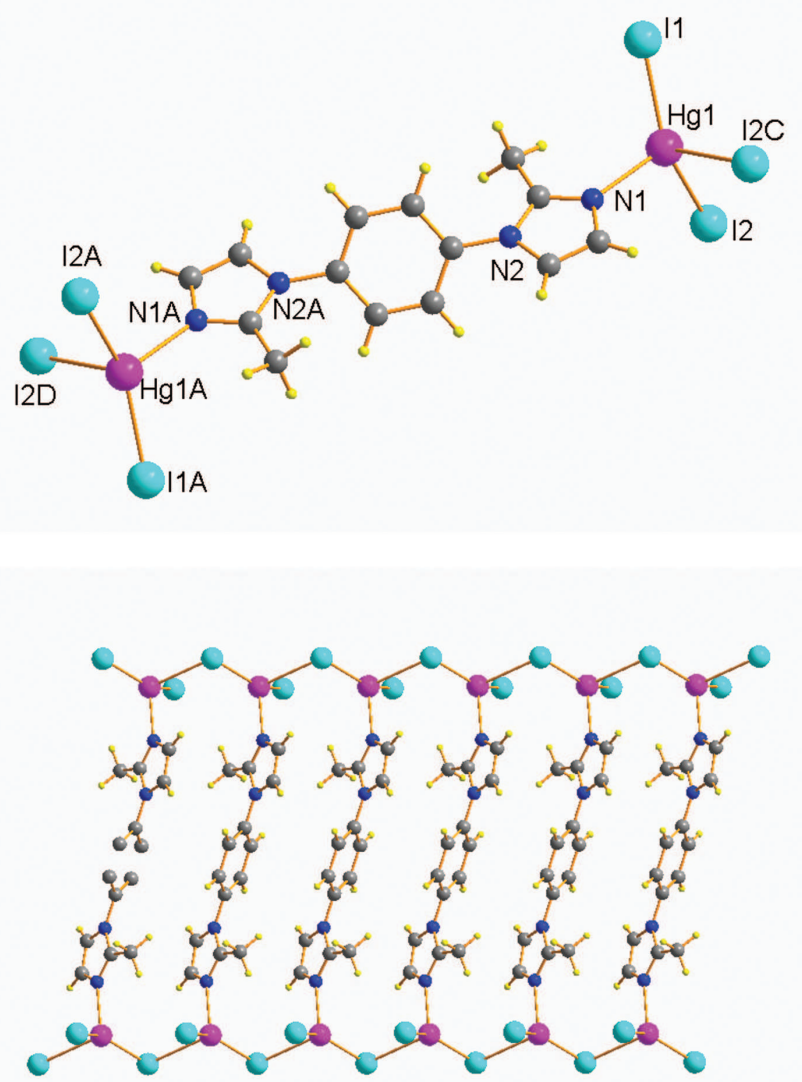

https://doi.org/10.1515/ncrs-2018-0271

Received July 29, 2018; accepted November 18, 2018; available online December 5, 2018

\section{Abstract}

$\mathrm{C}_{14} \mathrm{H}_{14} \mathrm{Hg}_{2} \mathrm{I}_{4} \mathrm{~N}_{4}, \quad$ monoclinic, $\quad P 2_{1} / c, \quad a=4.3592(11) \AA$, $b=20.116(5) \AA, c=12.713(3) \AA, \quad \beta=96.838(5)^{\circ}, Z=2, V=$ 1106.9(5) $\AA^{3}, \quad R_{\mathrm{gt}}(F)=0.0362, \quad w R_{\mathrm{ref}}\left(F^{2}\right)=0.0863$, $T=296(2) \mathrm{K}$.

*Corresponding author: Jia-Cheng Liu, College of Chemistry and Chemical Engineering, Northwest Normal University, Lanzhou 730070, P.R. China, e-mail: jcliuchem@163.com

Bing-Jie Hou, Ibrahim Omar Osman and Dong-Cheng Hu: College of Chemistry and Chemical Engineering, Northwest Normal University, Lanzhou 730070, P.R. China

\section{CCDC no.: 1857900}

Tables 1 and 2 contain details on crystal structure and measurement conditions and a list of the atoms including atomic coordinates and displacement parameters.

Table 1: Data collection and handling.

\begin{tabular}{ll}
\hline Crystal: & Yellow block \\
Size: & $0.25 \times 0.22 \times 0.19 \mathrm{~mm}$ \\
Wavelength: & Mo $K \alpha$ radiation $(0.71073 \AA)$ \\
$\mu:$ & $19.4 \mathrm{~mm}^{-1}$ \\
Diffractometer, scan mode: & Bruker APEX-II, $\varphi$ and $\omega$ \\
$\theta_{\max }$, completeness: & $25.5^{\circ},>99 \%$ \\
$N(h k l)_{\text {measured }}, N(h k l)_{\text {unique }}, R_{\text {int }}:$ & $6289,2054,0.041$ \\
Criterion for $I_{\text {obs }}, N\left(h k l_{\text {gt }}:\right.$ & $I_{\text {obs }}>2 \sigma\left(I_{\text {obs }}\right), 1799$ \\
$N(\text { param })_{\text {refined }}:$ & 110 \\
Programs: & SHELX [1, 2], CrysAlis ${ }^{\text {PRO }[3]}$ \\
\hline
\end{tabular}

Table 2: Fractional atomic coordinates and isotropic or equivalent isotropic displacement parameters $\left(\AA^{2}\right)$.

\begin{tabular}{lrrrr}
\hline Atom & $\boldsymbol{x}$ & $\boldsymbol{y}$ & $\boldsymbol{z}$ & $\boldsymbol{U}_{\text {iso }} \boldsymbol{U}_{\text {eq }}$ \\
\hline Hg1 & $0.39779(12)$ & $0.31347(2)$ & $0.46968(4)$ & $0.04825(16)$ \\
C1 & $0.126(2)$ & $0.4790(5)$ & $0.0992(8)$ & $0.032(2)$ \\
C2 & $-0.030(3)$ & $0.5385(5)$ & $0.0869(8)$ & $0.039(2)$ \\
H2 & -0.0487 & 0.5649 & 0.1458 & $0.047^{*}$ \\
C3 & $0.158(2)$ & $0.4406(5)$ & $0.0114(8)$ & $0.035(2)$ \\
H3 & 0.2665 & 0.4007 & 0.0188 & $0.042^{*}$ \\
C4 & $0.038(3)$ & $0.3416(6)$ & $0.2018(9)$ & $0.050(3)$ \\
H4A & -0.0167 & 0.3131 & 0.2573 & $0.075^{*}$ \\
H4B & 0.1550 & 0.3168 & 0.1559 & $0.075^{*}$ \\
H4C & -0.1470 & 0.3583 & 0.1618 & $0.075^{*}$ \\
C5 & $0.225(2)$ & $0.3978(5)$ & $0.2486(8)$ & $0.036(2)$ \\
C6 & $0.518(3)$ & $0.4601(5)$ & $0.3574(8)$ & $0.042(3)$ \\
H6 & 0.6445 & 0.4738 & 0.4175 & $0.050^{*}$ \\
C7 & $0.440(3)$ & $0.4974(5)$ & $0.2720(8)$ & $0.041(2)$ \\
H7 & 0.4979 & 0.5413 & 0.2621 & $0.049^{*}$ \\
I1 & $0.60515(18)$ & $0.20475(4)$ & $0.38664(7)$ & $0.0480(2)$ \\
I2 & $0.00610(16)$ & $0.35980(4)$ & $0.60039(6)$ & $0.0457(2)$ \\
N1 & $0.383(2)$ & $0.3981(5)$ & $0.3440(7)$ & $0.043(2)$ \\
N2 & $0.2585(19)$ & $0.4585(4)$ & $0.2018(6)$ & $0.0331(18)$ \\
\hline
\end{tabular}

๖ Open Access. ( 2019 Bing-Jie Hou et al., published by De Gruyter. (cc) BY This work is licensed under the Creative Commons Attribution 4.0 Public License. 


\section{Source of material}

A mixture of 1,4-bis(2-methyl-1 $\mathrm{H}$-imidazol-1-yl)benzene (23.8 mg, $\quad 0.1 \mathrm{mmol})$, mercury(II) iodide (136.3 mg, $0.3 \mathrm{mmol}), 1 \mathrm{~mL}$ ethanol and $6 \mathrm{~mL}$ distilled water were added in a Teflon-lined autoclave and then heated to $140{ }^{\circ} \mathrm{C}$ for $72 \mathrm{~h}$ before cooled to room temperature. Yellow block crystals were obtained in $63 \%$ yield (based on 1,4-bis(2-methyl-1Himidazol-1-yl)benzene), washed with deionized water, and dried in air. Anal. Calcd. for $\mathrm{C}_{7} \mathrm{H}_{7} \mathrm{HgI}_{2} \mathrm{~N}_{2}$ (573.54): C, 14.66; H, 1.23; N, 4.88\%. Found: C, 14.21; H, 1.20; N, 4.96\%.

\section{Experimental details}

All hydrogen atoms were placed at calculated positions and refined with a riding model, with $\mathrm{d}(\mathrm{C}-\mathrm{H})=0.93 \AA$ and $0.96 \AA$ $\left(\mathrm{CH}_{3}\right) . U_{\text {iso }}$ parameters of hydrogen atoms were set to $1.5 U_{\text {eq }}(\mathrm{C})$ for methyl groups and $1.2 U_{\text {eq }}(C)$ otherwise.

\section{Comment}

Coordination polymers (CPs) have attracted great attention because of their molecular topologies, properties, and potential applications in the fields of materials [3-7]. Imidazole derivatives have been widely used as ligands in bioinorganic chemistry, cluster science, and building blocks of supermolecular frameworks [8-10]. The rigid bisimidazole ligand, 1,4-bis(2-methyl- $1 \mathrm{H}$-imidazol1-yl)benzene, as the building unit, which features one special characteristics: the free rotation of imidazole rings can promote the flexibility of the ligand to meet the requirements of coordination geometries of metal ions for tuning the fine structure. The bisimidazole ligands not only act as bidentate ligand to coordinate two metal ions but can also be used to assemble supramolecular architectures.

The asymmetric unit of the title compound consists of one crystallographically independent $\mathrm{Hg}$ (II) ion, one half 1,4bis(2-methyl-1 $H$-imidazol-1-yl)benzene ligand, and two iodide anions. Each $\mathrm{Hg}$ (II) cation is four-coordinated with three iodide anions and one nitrogen atom from the bisimidazole ligand to form distorted tetrahedron geometry (upper part of the figure; $\mathrm{A}=-\mathrm{x}, 1-\mathrm{y},-\mathrm{z} ; \mathrm{B}=-1-x, 1-y,-z$; $\mathrm{C}=1+x, y, z)$. The bond lengths of $\mathrm{Hg}-\mathrm{I}$ vary slightly in the range of 2.6351(9) $\AA-3.1005(10) \AA$, and the $\mathrm{Hg}-\mathrm{N}$ distance is 2.331(9) $\AA$, both of which are in the normal range [10-12]. The involving $\mathrm{Hg}$ atoms bond angles of $\mathrm{I}(1)-\mathrm{Hg}(1)-$ $\mathrm{I}(2), \mathrm{I}(1)-\mathrm{Hg}(1)-\mathrm{N}(1), \mathrm{I}(2)-\mathrm{Hg}(1)-\mathrm{I}(2 \mathrm{C})$ and $\mathrm{I}(2)-\mathrm{Hg}(1)-\mathrm{N}(1)$ are $144.01(3)^{\circ}, 108.4(2)^{\circ}, 97.48(3)^{\circ}$ and $101.7(2)^{\circ}$, respectively. Each bisimidazole ligand linked two $\mathrm{Hg}$ (II) ions through N1 and N1A to generate a dinuclear secondary building unit (SBU). Each SBU is linked by two iodide anions to yield a 1D ladder-like coordination polymer chain (lower part of the figure).
Acknowledgements: This work was supported by grants from the Natural Science Foundation of China (Nos. 21761031 and 21461023) and Gansu Provincial Natural Science Foundation of China (No. 1606RJZA110).

\section{References}

1. Sheldrick, G. M.: Program for empirical absorption correction for area detector data. University of Göttingen, Göttingen, Germany (2014).

2. Sheldrick, G. M.: Crystal structure refinement with SHELXL. Acta Crystallogr. C71 (2015) 3-8.

3. Agilent Technologies: CrysAlis ${ }^{\text {PRO }}$ Software system, Agilent Technologies Ltd, Oxford, UK (2015).

4. Rachuri, Y.; Parmar, B.; Bisht, K. K.; Suresh, E.: Multiresponsive adenine-based luminescent $\mathrm{Zn}$ (II) coordination polymer for detection of $\mathrm{Hg}^{2+}$ and trinitrophenol in aqueous media. Cryst. Growth Des. 17 (2017) 1363-1372.

5. Dey, A.; Konavarapu, S. K.; Sasmal, H. S.; Biradha, K.: Porous coordination polymers containing pyridine-3,5-bis(5azabenzimidazole): exploration of water sorption, selective dye adsorption, and luminescent properties. Cryst. Growth Des. 16 (2016) 5976-5984.

6. Foo, M. L.; Matsuda, R.; Hijikata, Y.; Krishna, R.; Sato, H.; Horike, S.; Hori, A.; Duan, J. G.; Sato, Y.; Kubota, Y.; Takata, M.; Kitagawa, S.: An adsorbate discriminatory gate effect in a flexible porous coordination polymer for selective adsorption of $\mathrm{CO}_{2}$ over $\mathrm{C}_{2} \mathrm{H}_{2}$. J. Chem. Soc. 138 (2016) 3022-3030.

7. Si, C. D.; Hu, D. C.; Fan, Y.; Dong, X. Y.; Yao, X. Q.; Yang, Y. X.; Liu, J. C.: Three-dimensional supramolecular architectures with Coll ions assembled from hydrogen bonding and $\pi \cdots \pi$ stacking interactions: crystal structures and antiferromagnetic properties. Cryst. Growth Des. 15 (2015) 5781-5793.

8. Fan, Y.; Si, C. D.; Hou, C.; Yao, X. Q.; Hu, D. C.; Yang, Y. X.; Liu, J. C.: Three complexes of manganese(II) based on a new semirigid tetracarboxylate and $\mathrm{N}$-containing ligands: synthesis, crystal structures and magnetic properties. Polyhedron $\mathbf{9 8}$ (2015) 64-70.

9. Hu, D. C.; Fan, Y.; Si, C. D.; Wu, Y. J.; Dong, X. Y.; Yang, Y. X.; Yao, X. Q.; Liu, J. C.: A series of $\mathrm{Zn} / \mathrm{Cd}$ coordination polymers constructed from 1,4-naphthalenedicarboxylate and $\mathrm{N}$-donor ligands: syntheses, structures and luminescence sensing of $\mathrm{Cr}^{3+}$ in aqueous solutions. J. Solid State Chem. 241 (2016) 198-204.

10. Orsi, A.; Price, D. J.; Kahr, J.; Pillai, R. S.; Sneddon, S.; Cao, S.; Benoit, V.; Lozińska, M. M.; Cordes, D. B.; Slawin, A. M. Z.; Slawin, P. M. Z.; Casely, I.; Ashbrook, S. E.; Maurin, G.; Wrigh, P. A.: Porous zinc and cobalt 2-nitroimidazolate frameworks with six-membered ring windows and a layered cobalt 2nitroimidazolate polymorph. CrystEngComm 19 (2017) 1377-1388.

11. Guo, X.; Yan, Y.; Guo, H.; Qi, Y.; Liu, C.: Seven entangled coordination polymers assembled from triphenylamine-based bisimidazole and dicarboxylates: interpenetration, selfpenetration and mixed entanglement. CrystEngComm 18 (2016) 2546-2558.

12. Mobin, S. M.; Srivastava, A. K.; Mathur, P.; Lahiri, G. K.: Reversible single-crystal to single-crystal transformations in a $\mathrm{Hg}$ (II) derivative. $1 \mathrm{D}$-polymeric chain $\rightleftharpoons 2 \mathrm{D}$-networking as a function of temperature. Dalton Trans. 39 (2010) 8698-8705. 